Analisis Pengendalian Kualitas dan Usulan Perbaikan Pada........

\section{ANALISIS PENGENDALIAN KUALITAS DAN USULAN PERBAIKAN PADA PROSES EDGING DI PT RACKINDO SETARA PERKASA DENGAN METODE SIX SIGMA}

Hendy Tannady ${ }^{1}$, Calvin Chandra

E-mail: hendytannady@yahoo.com ${ }^{1}$

\section{Penulis}

Hendy Tannady adalah dosen tetap program studi Teknik Industri Universitas Bunda Mulia. Menyelesaikan pendidikan Sarjana Teknik Industri Universitas Bina Nusantara dan melanjutkan pendidikan Master Teknik Industri di Universitas Pelita Harapan.

Bidang peminatan: Simulasi, Antrian dan Perancangan Fasilitas.

\section{Abstract}

This research aims to improve the quality of processes and products on PT Rackindo Setara Perkasa, especially in Meja A edging process. This research is using six sigma method with the steps of DMAIC (define, measure, analyze, improve, control). The results of this research is there are three types of defects that found in the edging process. The defects are existing on paper connection, paper edging is not long enough and the maal edging is stuck. Based on the Pareto diagram, the improvements focused on the problem of paper connection and paper edging that is not long enough. Both defects are analyzed using the fishbone diagram to describe the causes of defects. From the analysis that uses $5 \mathrm{WIH}$ and solution tree, the conclusion of this study are the identification of several factors that cause defects, and recommendations for improvement in edging process, by making a training for the operators of edging process, making the written SOP on edging machine, making instructions about the engine setting, additional facilities on the roller of edging machine and the addition of compressor unit. By doing the improvement, it is expected an increase of sigma value from 4,22 into 4,71.

\section{Keywords}

Six Sigma, DMAIC, Statistical Tools, Capability Process, 5W1H
JIEMS

Journal of Industrial Engineering \& Management Systems Vol. 9, No 2, August 2016 
Analisis Pengendalian Kualitas dan Usulan Perbaikan Pada........

JIEMS

Journal of Industrial Engineering \& Management Systems Vol. 9, No 2, August 2016

\section{PENDAHULUAN}

Perkembangan industri di era globalisasi saat ini mengakibatkan meningkatnya persaingan antar perusahaan baik di bidang manufaktur maupun jasa. Dengan persaingan yang semakin ketat mengharuskan setiap perusahaan untuk meningkatkan kualitas produk atau jasa yang diberikan pada konsumen. Oleh sebab itu, maka perusahaan perlu untuk memahami setiap keinginan dari konsumen agar dapat memberikan kepuasan bagi pelanggan. Kemampuan perusahaan untuk dapat memuaskan keinginan pelanggan menjadi suatu hal penting yang menentukan nilai kualitas dari produk atau jasa yang ditawarkan.

PT Rackindo Setara Perkasa adalah salah satu perusahaan manufaktur yang bergerak di bidang manufaktur knock-down furniture di indonesia. Pada proses pembuatan Meja A saat ini masih ditemukan kecacatan yang terjadi pada proses edging komponen Meja A. Oleh karena itu penelitian ini dilakukan untuk menangani masalah tersebut. Untuk menganalisa permasalahan yang terjadi menggunakan metode six sigma.

Six Sigma merupakan proses disiplin tinggi yang membantu mengembangkan dan mengantarkan produk mendekati sempurna. Six Sigma adalah cara mengukur proses, tujuan mendekati sempurna, disajikan dengan 3,4 Defect Per Million Opportunities (DPMO), sebuah pendekatan untuk mengubah budaya organisasi. Salah satu metodologi dalam upaya peningkatan menuju target Six Sigma adalah DMAIC yang memberikan langkah dari menemukan permasalahan, mengidentifikasi penyebab masalah hingga akhirnya menemukan solusi untuk memperbaikinya. Beberapa tahapan dalam DMAIC yaitu Define (mendefinisikan masalah), Measure (pengukuran), Analysis (analisa), Improve (pengembangan), Control (pengendalian). Six sigma dapat digunakan untuk menemukan karakteristik-karakteristik yang penting untuk pelanggan, mengidentifikasi faktorfaktor yang mempengaruhi karakterisitik dan mengurangi variasi pada faktorfaktor kunci tersebut. Oleh karena itu, penelitian mengenai six sigma perlu dikaji dalam rangka perbaikan yang terus menerus (continuous improvement).

Dengan penyusunan penelitian ini diharapkan dapat menganalisis proses pengendalian kualitas pada PT Rackindo Setara Perkasa dengan menggunakan metode six sigma dan membuat suatu usulan perbaikan sehingga dapat meminimalisir jumlah produk cacat yang terjadi pada proses edging dan menambah nilai sigma pada perusahaan tersebut.

\section{LANDASAN TEORI Kualitas}

Pengertian kualitas mempunyai cakaupan yang sangat luas, relatif, berbedabeda dan berubah-ubah. Sehingga pada dasarnya pengertian kualitas yang memiliki banyak kriteria harus disesuaikan lagi berdasarkan konteksnya terutama jika dilihat dari sisi penilaian akhir konsumen dan definisi yang diberikan oleh berbagai ahli serta dari sudut pandang produsen sebagai pihak yang menciptakan kualitas.

Adapun pengertian kualitas menurut American Society for Quality yang dikutip oleh Heizer dan Render (2009) adalah keseluruhan corak dan karakteristik dari produk atau jasa yang berkemampuan untuk memenuhi kebutuhan yang tampak jelas maupun yang tersembunyi. Nasution (2005) mengumgkapkan para ahli kualitas juga mempunyai pendapat yang berbeda tentang pengertian kualitas, diantaranya adalah:

a. Menurut Crosby (1979) menyatakan bahwa kualitas harus sesuai dengan persyaratan dan standar yang telah ditentukan oleh perusahaan 
Analisis Pengendalian Kualitas dan Usulan Perbaikan Pada........

JIEMS

Journal of Industrial Engineering \& Management Systems Vol. 9, No 2, August 2016 b. Deming (1982) menyatakan, bahwa kualitas adalah kesesuaian dengan kebutuhan pasar.

c. Menurut Prawirosentono (2007), pengertian kualitas suatu produk adalah keadaan fisik, fungsi, dan sifat suatu produk bersangkutan yang dapat memenuhi selera dan kebutuhan konsumen dengan memuaskan sesuai nilai uang yang telah dikeluarkan.

\section{Pengendalian Kualitas}

Menurut Basterfield (2009), pengendalian kualitas adalah penggunaan teknik dan kegiatan untuk mencapai, mempertahankan, dan meningkatkan kualitas pelayanan dari produk. Menurut Gasperz (2005) yang dikutip oleh Chandra (2014), pengendalian kualitas adalah teknik operasional dan kegiatan yang digunakan untuk memenuhi persyaratan untuk kualitas. Berdasarkan pengertian di atas, dapat disimpulkan bahwa pengendalian kualitas adalah sebuah teknik operasional dan kegiatan yang digunakan untuk mencapai, mempertahankan, dan meningkatkan persyaratan untuk kualitas suatu produk tersebut.

\section{Six Sigma}

Six sigma merupakan suatu pendekatan bagi pengambilan keputusan dalam usaha peningkatan proses yang didesain untuk meningkatkan produktivitas dan mengurangi biaya-biaya. Tahapan dari Six Sigma adalah sebagai berikut:

\section{a. Define}

Mengklarifikasi masalah, tujuan dan proses. Membuat pernyataan masalah sedapat mungkin spesifik dan berdasarkan fakta, fokuskan kepada apa yang dapat diamati dan disusun, bukan pada perkiraan atau asumsi-asumsi. Kemudian tentukan tujuan yang akan dicapai.

b. Measure

Mendasarkan dan menyaring masalah. Memvalidasi atau menyaring masalah dan memulai meneliti akar masalah, memperhatikan output yang dihasilkan dan melihat pengaruhnya terhadap pengguna sistem, serta menemukan komponen yang paling signifikan pada masalah, sehingga analisa dan solusi akan ditargetkan dengan baik.

c. Analyze

Analisa akar masalah. Melihat pada proses dan data untuk mengidentifikasi penyebab-penyebab yang mungkin, menemukan penyebab yang diperkirakan dan berusaha memvalidasinya melalui analisis.

d. Improve

Menghasilkan, memilih dan mengimplementasi solusi-solusi Menemukan ideide yang mungkin akan membantu kita mengatasi akar masalah dan mencapai tujuan, menentukan ide mana yang menjadi solusi-solusi potensial, dan memilih solusi yang paling tepat dengan biaya dan gangguan yang paling sedikit. Pada akhirnya menguji solusi yang kita pilih untuk memastikan keefektifannya kemudian mengimplementasikannya secara permanen.

e. Control

Memperbaiki kesalahan-kesalahan yang muncul setelah pengimplementasian dan menetapkan standar untuk menjaga efektivitas kinerja serta melakukan review.

\section{METODOLOGI}

Penelitian ini dilakukan berdasarkan tahapan DMAIC yang sistematik dengan langkah-langkah sebagai berikut. 
Analisis Pengendalian Kualitas dan Usulan Perbaikan Pada.......

\section{JIEMS}

Journal of Industrial Engineering \& Management Systems

Vol. 9, No 2, August 2016

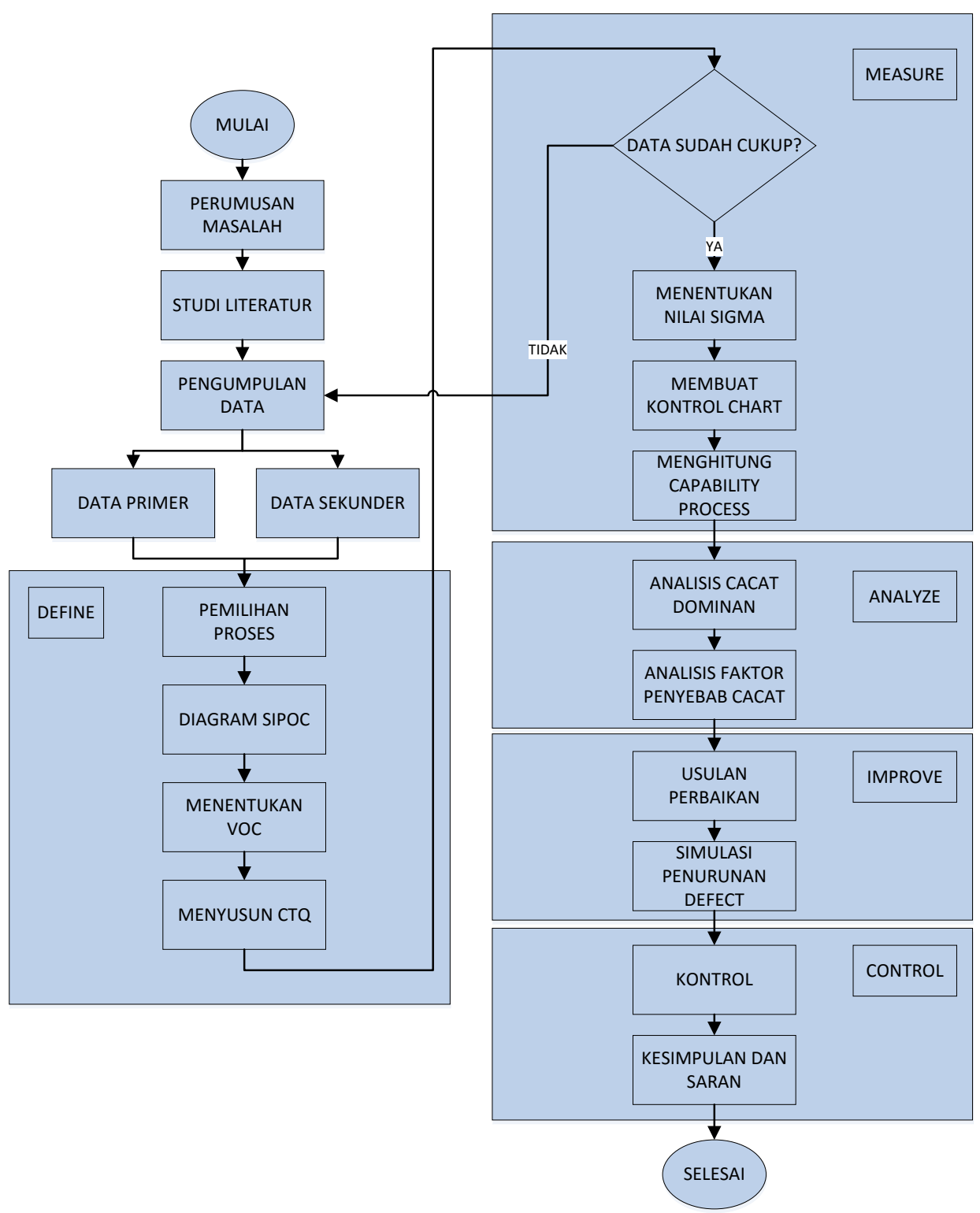

Gambar 1. Diagram Alir Metode Penelitian

\section{HASIL DAN PEMBAHASAN}

Proses Produksi

Berikut adalah penggambaran dari alur proses produksi dari pembuatan Meja A.

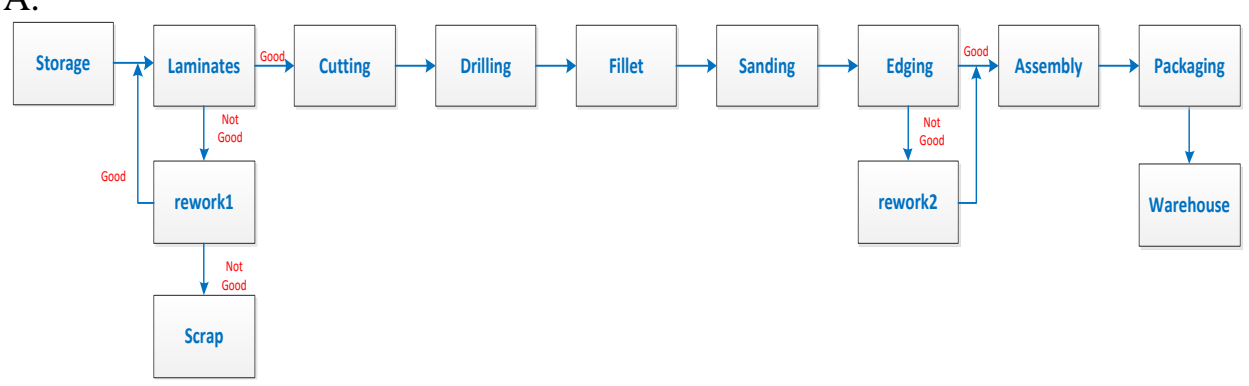

Gambar 2. Proses Produksi Meja A 
Analisis Pengendalian Kualitas dan Usulan Perbaikan Pada........

JIEMS

Journal of Industrial Engineering \& Management Systems Vol. 9, No 2, August 2016
Dibawah ini adalah uraian mengenai urutan alur proses produksi Meja A.

a. Storage, merupakan tempat penyimpanan material yang akan memasuki proses laminates, dimana di storage berisikan material kayu panel, kertas, lem serta material lainya.

b. Laminates, merupakan proses pelapisan kayu panel utuh dengan paper, dengan menggunakan lem. Proses laminasi ini dilakukan dengan menggunakan mesin laminating yang akan menghasilkan output berupa kayu panel yang telah terlapis oleh paper sesuai dengan warna paper yang telah ditentukan. Proses pelapisan sempurna akan masuk proses selanjutnya, sedangkan yang mengalami cacat akan masuk ke proses rework 1.

c. Rework 1, merupakan proses pengerjaan ulang terhadap panel kayu yang tidak sempurna dilaminasi. Kegagalan proses laminasi hanyalah sebatas pengeleman yang kurang merata sehingga kertas tidak menempel sempurna. Proses pengerjaan rework 1 adalah pelepasan laminasi yang gagal. Setelah berhasil dilepaskan, maka akan dimasukkan kembali ke proses laminates kembali.

d. Scrap, merupakan proses pembuangan kayu panel yang tidak berhasil diperbaiki pada proses rework 1 .

e. Cutting, merupakan proses pemotongan kayu panel utuh yang telah terlaminasi. Proses pemotongan ini akan menghasilkan beberapa komponen meja A.

f. Fillet, merupakan proses pengikisan siku komponen meja A menjadi lebih tumpul dan halus.

g. Sanding, merupakan proses penghalusan sisi-sisi komponen baik yang sudah terlaminasi atau belum. Penghalusan ini dilakukan agar komponen menjadi lebih halus dan menghilangkan sisi - sisi kayu yang masih kasar.

h. Edging, merupakan proses pelapisan pada sisi samping komponen-komponen kayu dengan paper seperti pada proses laminates yailu melapisi komponen kayu dengan paper, hanya saja pada roses ini melapisi sisi samping dari komponen yang telah melewati proses sanding tersebut.

i. Rework 2, merupakan proses pengerjaan ulang terhadap pelapisan sisi samping (edging) yang tidak terlaminasi dengan baik. Proses ini melakukan pemisahan antara komponen kayu dengan paper yang tidak menempel dengan sempurna setelah itu akan langung dilakukan penempelan sisi samping ulang.

j. Assembly, merupakan proses penggabungan komponen-komponen kayu dengan menggunakan paku tembak dimana peoses ini meliputi 2 komponen yang ingin disatukan yang sebelumna telah dilapsi oleh lem terlebih dahulu, lalu diperkuat dengan menggunakan paku tembak.

k. Packing, merupakan proses pengemasan komponen-komponen kayu produk $A$ dilengkapi dengan aksesesorisnya.

1. Warehouse, merupakan tempat penyimpanan meja A yang telah dikemas dan siap untuk dipasarkan.

\section{Jenis-jenis Defect}

Meja A dikatakan defect, dapat dilihat dari kondisi hasil pemprosesan yang telah dilakukan apakah sesuai dengan spesifikasi yang ditentukan. Berdasarkan data historis dari perusahaan, bagian yang menjadi pusat perhatian dalam proses produksi meja A adalah proses edging. Hal ini disebabkan karena proses ini memiliki jumlah defect terbanyak. Untuk proses lainnya seperti laminating, cutting, drilling, dll telah menggunakan mesin yang cukup canggih dan tidak menimbukan defect yang berarti. Berikut adalah defect yang terdapat pada proses edging: 
Analisis Pengendalian Kualitas dan Usulan Perbaikan Pada........
JIEMS

Journal of Industrial Engineering \& Management Systems Vol. 9, No 2, August 2016 a. Edging sambungan. Cacat ini terlihat dengan terlihatnya sambungan pada hasil edging.

b. Edging kurang panjang. Cacat ini terlihat dengan hasil edging yang tidak menutupi semua bagian yang mengalami proses edging disebabkan lapisan penutup kurang panjang.

c. Tertahan maal edging. Tertahan oleh roller edging sehingga menyebabkan goresan pada hasil edging.

\section{Data Jumlah Produksi dan Defect Produk Meja A}

Tabel 1 menjelaskan data historis perusahaan mengenai jumlah produksi dan defect komponen produk Meja A selama periode produksi Februari 2016.

Tabel 1. Data Jumlah Produksi Komponen \& Defect Produk Meja A (Sumber: PT Rackindo Setara Perkasa, Februari 2016)

\begin{tabular}{|c|l|r|r|}
\hline No. & Komponen & Jumlah Produksi & Jumlah Cacat \\
\hline $\mathbf{1}$ & DM & 1080 & 9 \\
\hline $\mathbf{2}$ & A (kanan) & 1080 & 11 \\
\hline $\mathbf{3}$ & A (kiri) & 1080 & 11 \\
\hline $\mathbf{4}$ & B & 1080 & 3 \\
\hline $\mathbf{5}$ & RM1 & 1080 & 7 \\
\hline $\mathbf{6}$ & P (kanan) & 1080 & 24 \\
\hline $\mathbf{7}$ & P (kiri) & 1080 & 8 \\
\hline
\end{tabular}

\section{Tahap Define}

a. Pemilihan Proses

Dibawah ini akan menampilkan tabel perbandingan jumlah dan persentase cacat komponen Meja A yang terjadi pada proses edging.

Tabel 2. Tabel Jumlah Defect

\begin{tabular}{|c|c|c|c|c|c|c|}
\hline \multirow{2}{*}{ Komponen } & \multirow{2}{*}{ Jumlah Produksi } & \multicolumn{3}{|c|}{ Reject } & \multirow{2}{*}{ Total } & \multirow{2}{*}{ Persentase } \\
\hline & & C1 & C2 & C3 & & \\
\hline DM & 1080 & 6 & 3 & 0 & 9 & $0,83 \%$ \\
\hline A (kanan) & 1080 & 2 & 5 & 4 & 11 & $1,02 \%$ \\
\hline A (kiri) & 1080 & 5 & 4 & 2 & 11 & $1,02 \%$ \\
\hline B & 1080 & 0 & 3 & 0 & 3 & $0,28 \%$ \\
\hline RM1 & 1080 & 5 & 2 & 0 & 7 & $0,65 \%$ \\
\hline $\mathbf{P}($ kanan) & 1080 & 12 & 10 & 2 & 24 & $2,22 \%$ \\
\hline $\mathbf{P}$ (kiri) & 1080 & 3 & 3 & 2 & 8 & $0,74 \%$ \\
\hline Total & 7560 & 33 & 30 & 10 & 73 & $0,97 \%$ \\
\hline Rata - rata & 1080 & 4,71 & 4,29 & 1,43 & 10,43 & $0,97 \%$ \\
\hline
\end{tabular}

Keterangan: $\mathrm{C} 1=$ edging sambungan

$$
\begin{aligned}
& \mathrm{C} 2=\text { edging kurang panjang } \\
& \mathrm{C} 3=\text { mentok maal edging-an }
\end{aligned}
$$

Dibawah ini adalah jumlah defect berdasarkan sumber defect yang digambarkan dengan diagram batang dan pie chart. 
Analisis Pengendalian Kualitas dan Usulan Perbaikan Pada.......

\section{JIEMS}

Journal of Industrial Engineering \& Management Systems Vol. 9, No 2, August 2016

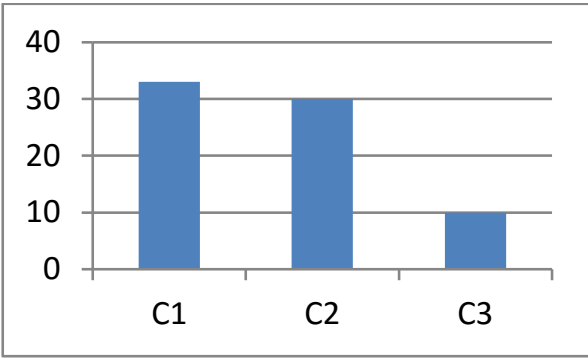

Gambar 3. Jumlah Defect Setiap Komponen

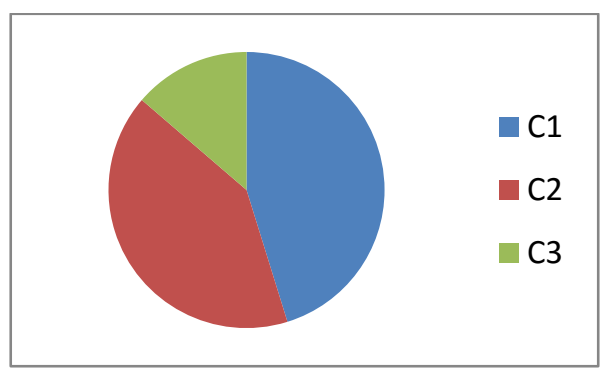

Gambar 4. Persentase per Jenis Defect

b. Diagram SIPOC

Dalam Gambar 5 akan dijelaskan alur input dan output dari setiap proses produksi yang ada, sebagai berikut:

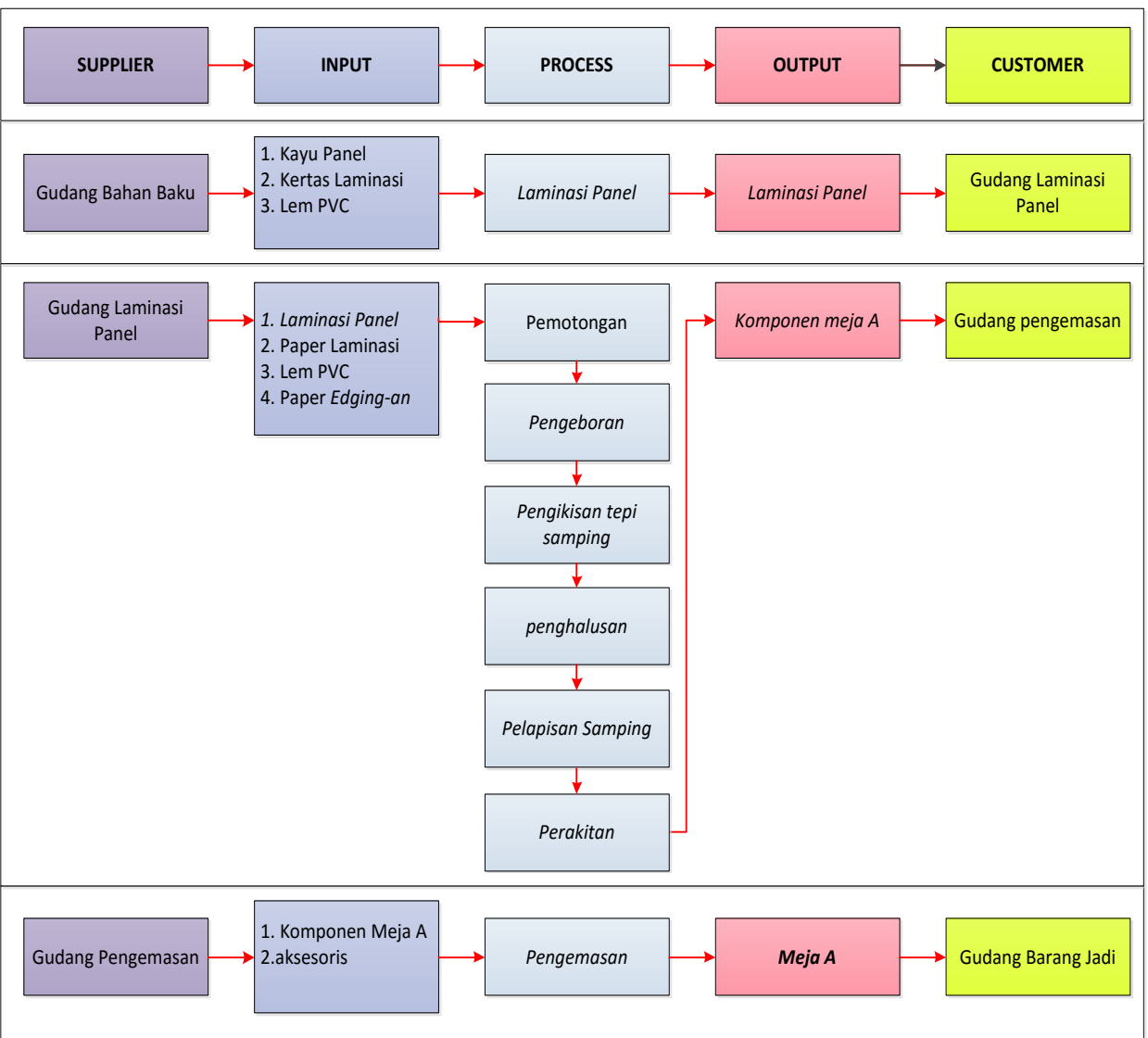

Gambar 5. Diagram SIPOC 
Analisis Pengendalian Kualitas dan Usulan Perbaikan Pada........

JIEMS

Journal of Industrial Engineering \& Management Systems Vol. 9, No 2, August 2016 c. Voice of Customer (VOC)

Berikut adalah Voice of Customer (VOC) dari meja A tersebut.

1. Meja A dapat berfungsi dengan baik.

2. Daya tahan tinggi (tidak mudah rusak).

3. Meja A mimiliki ukuran yang sesuai dengan standard dan dapat digunakan dengan baik.

4. Tampilan desain yang elegan dan menarik.

5. Adanya garansi produk untuk jangka waktu tertentu.

d. Critical to Quality (CTQ)

Penentuan CTQ ini dilakukan berdasarkan wawancara yang dilakukan dengan pihak perusahaan, dikemukakan enam kategori CTQ pada produk Meja A parabola, yaitu:

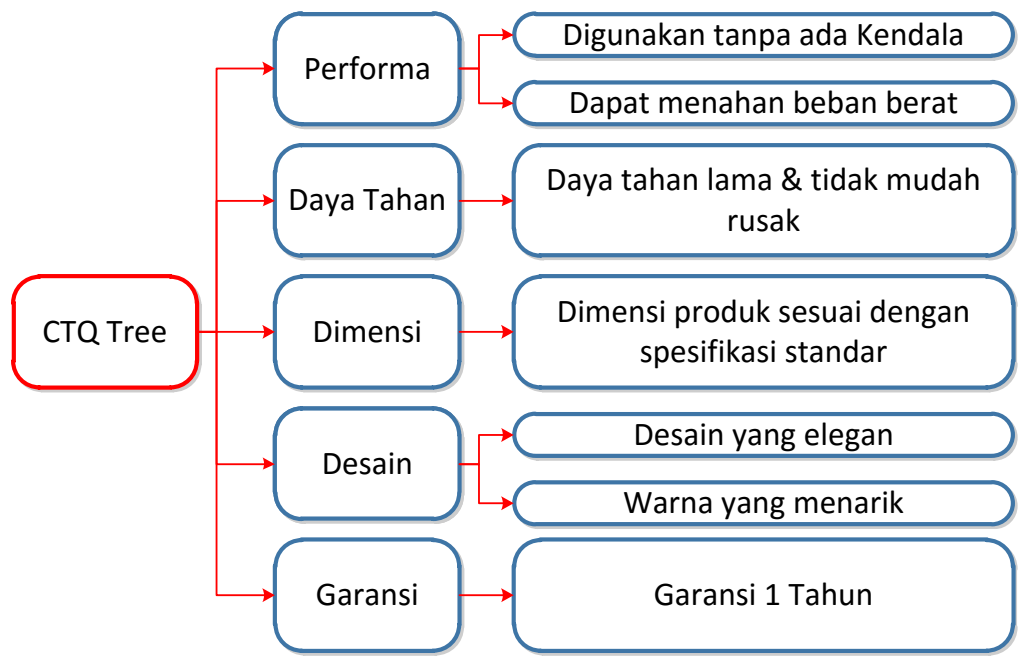

Gambar 6. CTQ Tree

Dari keenam jenis CTQ yang dikemukakan oleh pihak perusahaan tersebut, dapat diidentifikasikan jenis-jenis defect yang terjadi pada produk sebagai CTQ potensial penyebab kecacatan pada produk yang diteliti yaitu:

Tabel 3. Critical To Quality

\begin{tabular}{|c|l|}
\hline Kategori Defect & \multicolumn{1}{|c|}{ Nama Defect } \\
\hline Critical & Ada sambungan \\
\cline { 2 - 2 } & Kurang panjang \\
\hline Major & Cacat lekukan \\
\hline
\end{tabular}

Tahap Measure

a. Uji Kecukupan Data

$$
\begin{aligned}
& N^{\prime}=\frac{Z^{2} \times \bar{p} \times(1-\bar{p})}{\alpha^{2}} \\
& N^{\prime}=\frac{3^{2} \times 0,009656 \times(1-0,009656)}{(0,01)^{2}} \\
& N^{\prime}=860,648 \text { data }
\end{aligned}
$$


Analisis Pengendalian Kualitas dan Usulan Perbaikan Pada........
Berdasarkan perhitungan tersebut, didapatkan bahwa nilai $\mathrm{N}$ lebih besar dari nilai N', yaitu $7650>860,648$ yang artinya data telah mencukupi.

b. Perhitungan Control Chart NP

$$
\begin{array}{rlrl}
\overline{N P} & =\frac{\sum N P}{\sum n}=\frac{73}{7}=10,42857 & U C L & =\overline{N P}+3 S_{N P} \\
S_{N P} & =\sqrt{\overline{N P}(1-\bar{P})} & U C L & =10,42857+3(3,21370) \\
S_{N P} & =\sqrt{10,42857(1-0,00966)} & U C L & =20,06967 \\
S_{N P} & =3,21370 & L C L & =\overline{N P}-3 S_{N P} \\
C L & =\overline{N P}=10,42857 & L C L & =0,78747
\end{array}
$$

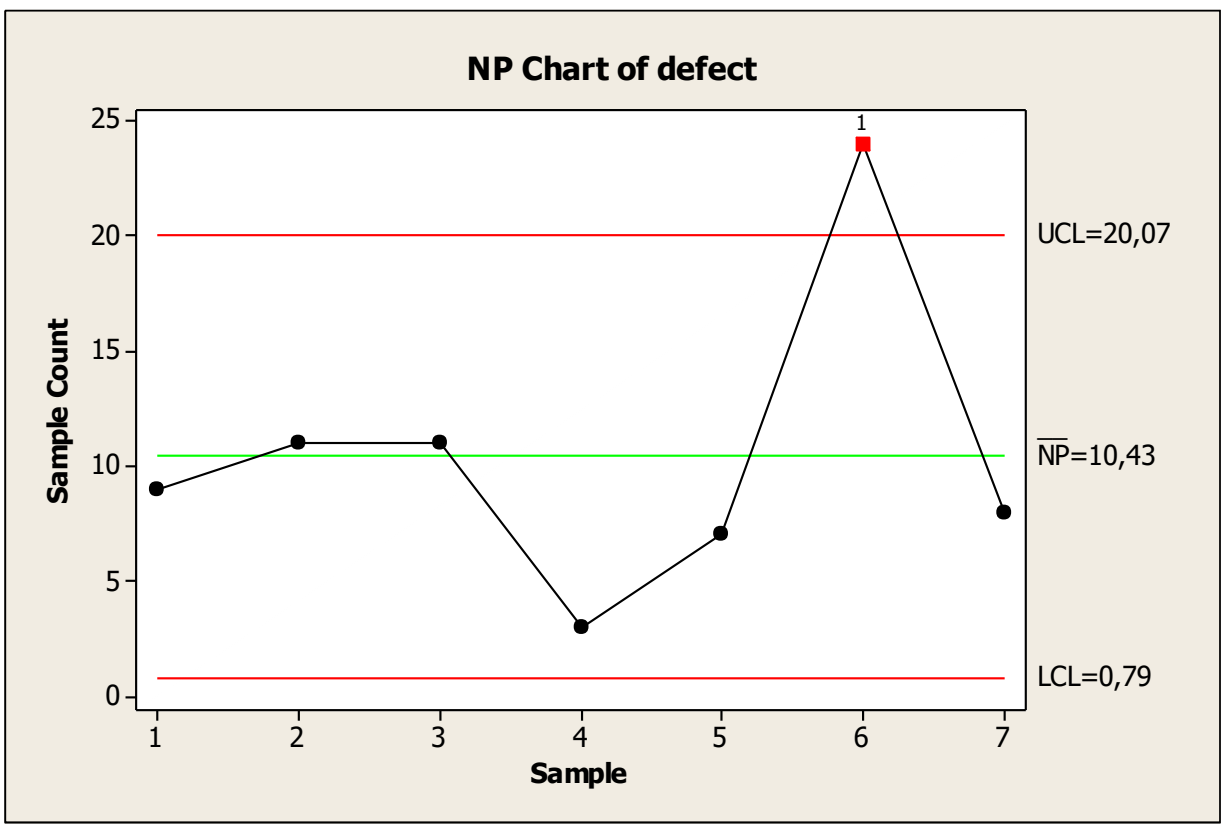

Gambar 7. Control Chart NP

Pada Gambar 7 ditemukan satu data diluar batas kendali. Dari hasil diskusi dengan kepala produksi PT Rackindo Setara Perkasa mengenai penyebab terjadinya data diluar batas kendali tersebut dikarenakan oleh faktor khusus yang terjadi, sehingga data tersebut sepakat untuk dihilangkan dalam perhitungan agar tidak mempengaruhi nilai dari data yang lain.

Perhitungan Control Chart NP (revisi 1)

\section{JIEMS}

Journal of Industrial Engineering \&

Management Systems

Vol. 9, No 2, August 2016 
Analisis Pengendalian Kualitas dan Usulan Perbaikan Pada........

\section{JIEMS}

Journal of Industrial Engineering \& Management Systems Vol. 9, No 2, August 2016

$$
\begin{array}{ll}
\overline{N P}=\frac{\sum N P}{\sum n}=\frac{49}{6}=8,16667 & U C L=\overline{N P}+3 S_{N P} \\
S_{N P}=\sqrt{\overline{N P}(1-\bar{P})} & U C L=8,16667+3(2,84691) \\
S_{N P}=\sqrt{8,16667(1-0,00756)} & U C L=16,70741 \\
S_{N P}=2,84691 & L C L=\overline{N P}-3 S_{N P} \\
C L=\overline{N P}=8,16667 & L C L=8,16667-3(2,84691) \\
\hline & L C L=-0,37470 \approx 0
\end{array}
$$

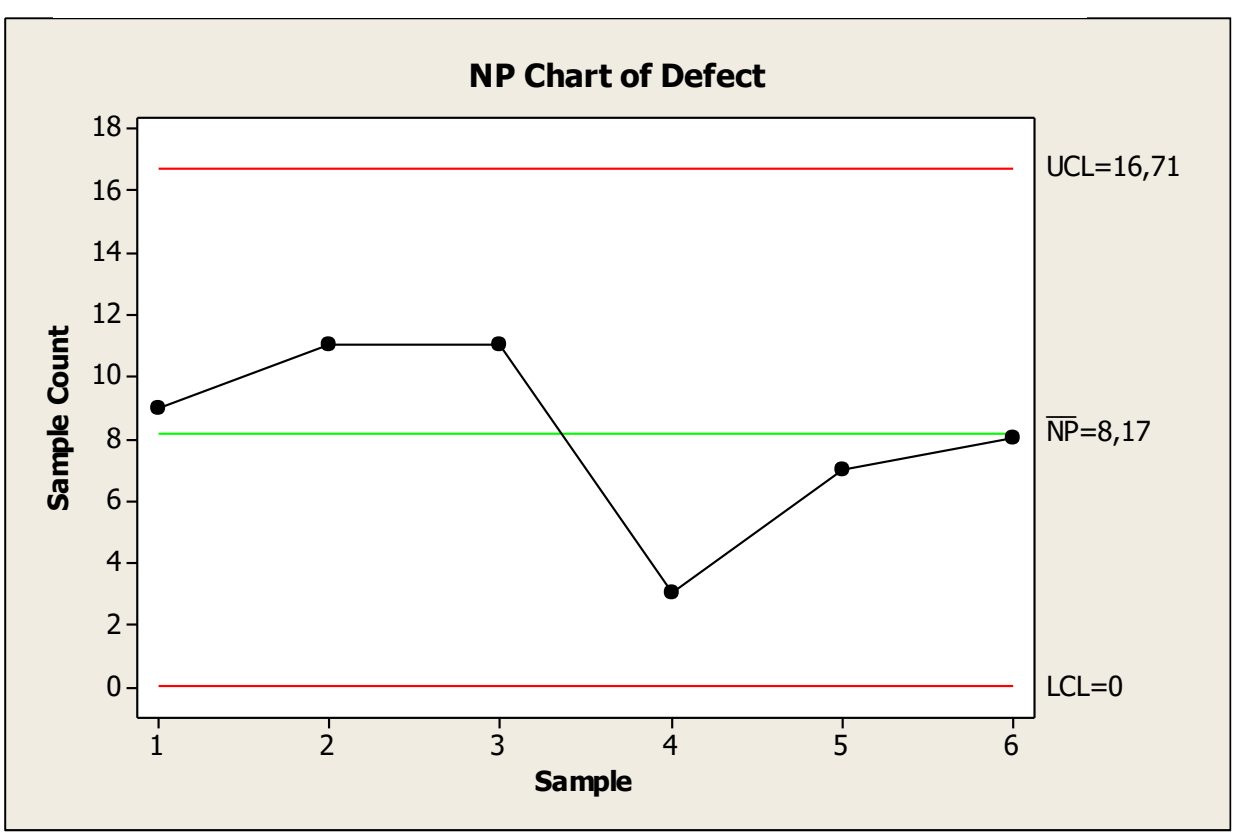

Gambar 8. Control Chart NP (revisi 1)

c. Perhitungan Capablity Process $(C p)$

$C p=1-\bar{P}=1-0,076=0,99240=99,24 \%$

Berdasarkan perhitungan didapatkan nilai $C p$ sebesar 99,24\%. Nilai ini masih kurang dari satu $(0,9924<C p<1)$, artinya masih dapat ditingkatkan kembali.

d. Perhitungan Nilai Sigma

Perhitungan DPMO (Defect Per Million Opportunities) dan level sigma dilakukan dengan langkah-langkah sebagai berikut.

1. Defect Per Unit (DPU)

$D P U=\frac{D}{U}=\frac{73}{7560}=0,0097$

2. Total Opportunities (TOP)

$T O P=U \times O P=7560 \times 3=22.680$

3. Defect Per Opportunities (DPO)

$D P O=\frac{D}{T O P}=\frac{73}{22680}=0,00322$ 
Analisis Pengendalian Kualitas dan Usulan Perbaikan Pada........
4. Defect Per Million Opportunities (DPMO)

$D P M O=D P O \times 1000000$

$D P M O=0,00322 \times 1000000$

$D P M O=3218,69489$

5. Sigma Level (Tingkat Sigma)

$$
\begin{aligned}
& \text { Sigma Level }=\text { normsinv }\left(\frac{1000000-D P M O}{1000000}\right)+1,5 \\
& \text { Sigma Level }=\text { normsinv }\left(\frac{1000000-3218,69489}{1000000}\right)+1,5 \\
& \text { Sigma Level }=4,22463 \approx \mathbf{4 , 2 2}
\end{aligned}
$$

\section{Tahap Analyze}

a. Analisa Cacat Dominan

Tabel 5. Tabel Jumlah Setiap Jenis Defect

\begin{tabular}{|l|r|r|r|r|}
\hline \multirow{2}{*}{ Jenis Defect } & \multicolumn{1}{|c|}{ Frekuensi } & \multicolumn{1}{|c|}{ Frekuensi } & \multicolumn{1}{|l|}{ Persentase } & \multicolumn{1}{l|}{ Persentase } \\
\cline { 2 - 5 } & \multicolumn{1}{|c|}{ Defect } & Kumulatif & & \multicolumn{1}{l|}{ Kumulatif } \\
\hline C1 & 33 & 33 & 0,452054795 & 0,452054795 \\
\hline C2 & 30 & 63 & 0,410958904 & 0,863013699 \\
\hline C3 & 10 & 73 & 0,136986301 & 1 \\
\hline Total & 73 & & 1 & \\
\hline
\end{tabular}

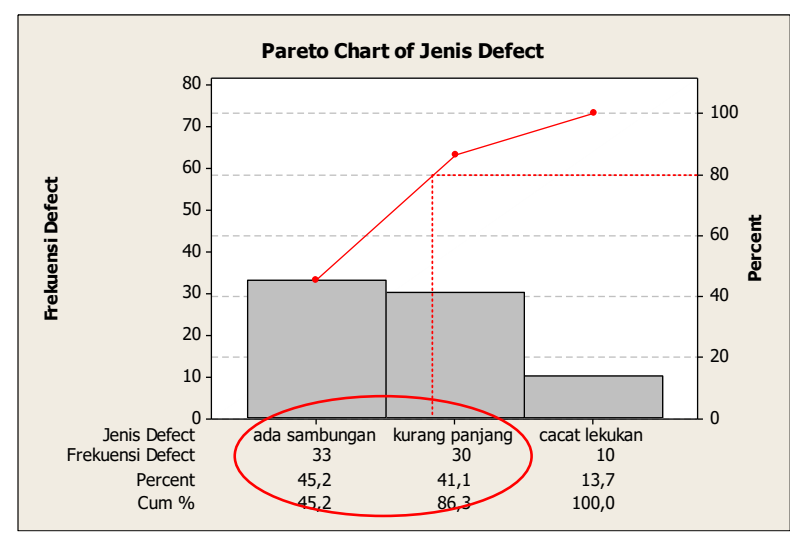

Gambar 9. Diagram Pareto Jenis Defect

Dari hasil pengamatan dapat diketahui bahwa $80 \%$ defect yang terjadi pada proses edging meja A bulan Februari 2016 didominasi oleh 2 jenis defect yaitu adanya sambungan dengan persentase $45,2 \%$, dan kurang panjang sebesar $41,1 \%$. Jadi perbaikan dapat dilakukan dengan memfokuskan pada 2 jenis defect terbesar tersebut.

\section{JIEMS}

Journal of Industrial Engineering \& Management Systems Vol. 9, No 2, August 2016 
Analisis Pengendalian Kualitas dan Usulan Perbaikan Pada....... b. Analisa Faktor-Faktor Penyebab Defect Dengan Diagram Sebab-Akibat (Fishbone Diagram)

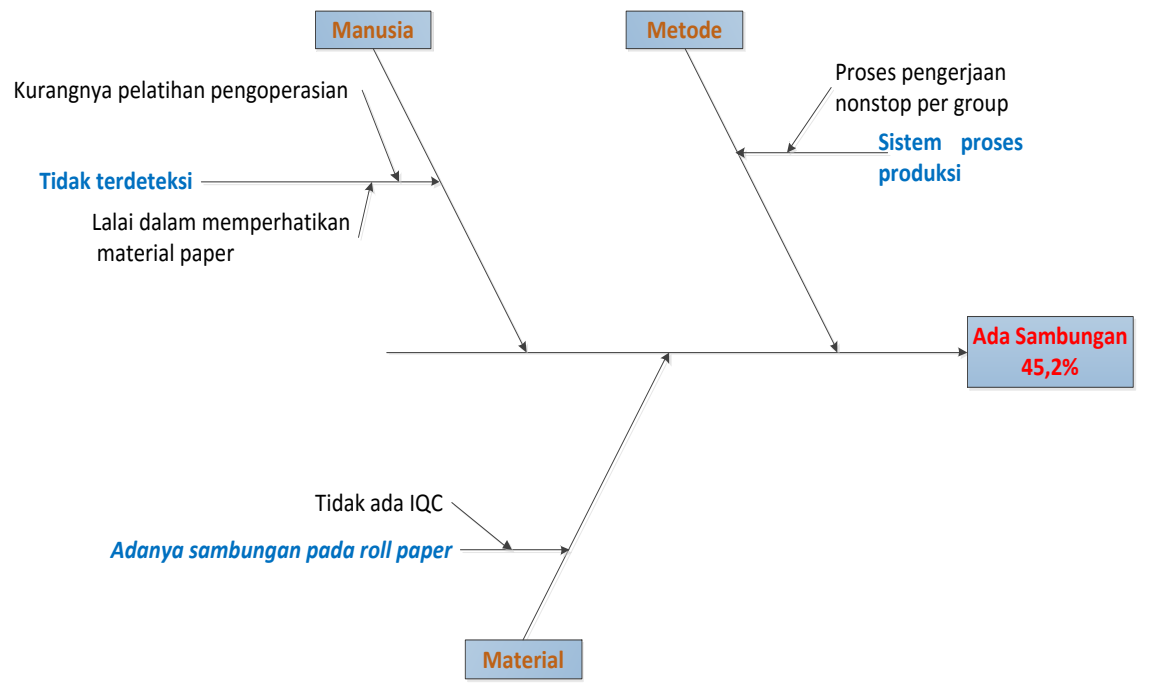

Gambar 10. Diagram Sebab-Akibat Untuk Ada Sambungan

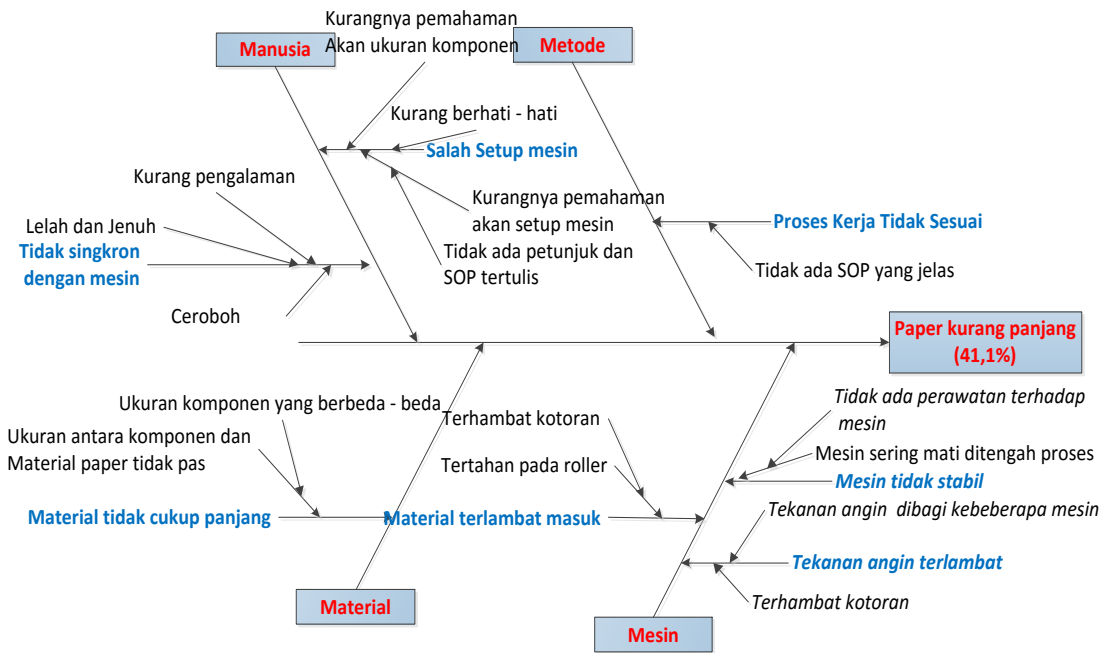

Gambar 10. Diagram Sebab-Akibat Untuk Paper kurang Panjang

\section{JIEMS}

Journal of Industrial Engineering \&

Management Systems

Vol. 9, No 2, August 2016 
Analisis Pengendalian Kualitas dan Usulan Perbaikan Pada........

\section{Tahap Improve}

Tabel 6. 5W1H

\begin{tabular}{|c|c|c|c|c|c|c|}
\hline \multirow{2}{*}{$\begin{array}{c}\text { Waktu } \\
\text { terjadi } \\
\text { (When } \\
\text { ) }\end{array}$} & \multirow{2}{*}{$\begin{array}{l}\text { Defect } \\
\text { yang } \\
\text { terjadi } \\
(\text { What })\end{array}$} & \multirow{2}{*}{$\begin{array}{l}\text { Sumber } \\
\text { terjadiny } \\
\text { a defect } \\
\text { (Where) }\end{array}$} & \multicolumn{2}{|c|}{ Akar permasalahan (why) } & \multirow{2}{*}{$\begin{array}{l}\text { Usulan } \\
\text { Perbaikan } \\
(\text { Who })\end{array}$} & \multirow{2}{*}{$\begin{array}{c}\text { PIC } \\
(w h o)\end{array}$} \\
\hline & & & $\begin{array}{c}\text { Faktor } \\
\text { Penyeba } \\
b\end{array}$ & $\begin{array}{c}\text { Penyebab } \\
\text { terjadinya } \\
\text { defect }\end{array}$ & & \\
\hline \multirow[t]{4}{*}{$\begin{array}{l}\text { Selam } \\
\text { a } \\
\text { proses } \\
\text { edgin } \\
g\end{array}$} & \multirow[t]{4}{*}{$\begin{array}{c}\text { Adanya } \\
\text { Sambunga } \\
\mathrm{n}\end{array}$} & \multirow[t]{4}{*}{$\begin{array}{l}\text { terjadi di } \\
\text { proses } \\
\text { edging }\end{array}$} & Material & $\begin{array}{l}\text { tidak adanya } \\
\text { inspeksi saat } \\
\text { menerima } \\
\text { setiap bahan } \\
\text { baku proses } \\
\text { edging pada } \\
\text { storage } \\
\end{array}$ & $\begin{array}{c}\text { adanya } \\
\text { inspeksi } \\
\text { terhadap } \\
\text { setiap } \\
\text { bahan } \\
\text { baku yang }\end{array}$ & $\overline{\mathrm{QC}}$ \\
\hline & & & \multirow[t]{2}{*}{ Manusia } & $\begin{array}{l}\text { lalai dalam } \\
\text { memperhatik } \\
\text { an paper. }\end{array}$ & \multirow{2}{*}{$\begin{array}{c}\text { memberika } \\
\text { n pelatihan } \\
\text { terkait } \\
\text { pada } \\
\text { proses } \\
\text { edging } \\
\text { pada setiap } \\
\text { operator }\end{array}$} & HRD \\
\hline & & & & $\begin{array}{c}\text { kurangnya } \\
\text { pelatihan } \\
\text { terhadap } \\
\text { operator }\end{array}$ & & \\
\hline & & & Metode & $\begin{array}{c}\text { sistem kerja } \\
\text { yang } \\
\text { diharuskan } \\
\text { pengerjaan } \\
\text { nonstop per } \\
\text { group } \\
\text { sehingga } \\
\text { material } \\
\text { paper yang } \\
\text { terdapat } \\
\text { sambungan } \\
\text { tidak terlihat }\end{array}$ & $\begin{array}{c}\text { adanya } \\
\text { pengkajian } \\
\text { ulang } \\
\text { sistem } \\
\text { kerja yang } \\
\text { sekarang }\end{array}$ & $\begin{array}{l}\text { kabag. } \\
\text { Produksi } \\
\text { dan } \\
\text { Supervis } \\
\text { or } \\
\text { produksi }\end{array}$ \\
\hline
\end{tabular}

\section{JIEMS}

Journal of Industrial Engineering \&

Management Systems

Vol. 9, No 2, August 2016 
Tabel 6. 5W1H (Lanjutan)

\begin{tabular}{|c|c|c|c|c|c|c|}
\hline \multirow{2}{*}{$\begin{array}{l}\text { Waktu } \\
\text { terjadi } \\
\text { (When) }\end{array}$} & \multirow{2}{*}{$\begin{array}{l}\text { Defect } \\
\text { yang } \\
\text { terjadi } \\
\text { (What) }\end{array}$} & \multirow{2}{*}{$\begin{array}{l}\text { Sumber } \\
\text { terjadinya } \\
\text { defect } \\
\text { (Where) }\end{array}$} & \multicolumn{2}{|c|}{$\begin{array}{l}\text { Akar permasalahan } \\
\text { (why) }\end{array}$} & \multirow{2}{*}{$\begin{array}{l}\text { Usulan } \\
\text { Perbaikan } \\
(W h o)\end{array}$} & \multirow[t]{2}{*}{ PIC (who) } \\
\hline & & & $\begin{array}{c}\text { Faktor } \\
\text { Penyebab }\end{array}$ & $\begin{array}{c}\text { Penyebab } \\
\text { terjadinya } \\
\text { defect }\end{array}$ & & \\
\hline \multirow[t]{7}{*}{$\begin{array}{l}\text { Selama } \\
\text { proses } \\
\text { edging }\end{array}$} & \multirow[t]{7}{*}{$\begin{array}{c}\text { Paper } \\
\text { kurang } \\
\text { panjang }\end{array}$} & \multirow[t]{7}{*}{$\begin{array}{l}\text { terjadi di } \\
\text { proses } \\
\text { edging }\end{array}$} & Material & $\begin{array}{c}\text { paper } \\
\text { tidak } \\
\text { cukup } \\
\text { panjang } \\
\text { karena } \\
\text { habis }\end{array}$ & $\begin{array}{c}\text { melakukan } \\
\text { penyesuaian } \\
\text { ukuran } \\
\text { terhadap } \\
\text { komponen } \\
\text { dengan } \\
\text { material } \\
\text { paper }\end{array}$ & $\begin{array}{l}\text { kabag. } \\
\text { Produksi }\end{array}$ \\
\hline & & & manusia & $\begin{array}{l}\text { gerakan } \\
\text { operator } \\
\text { tidak } \\
\text { sinkron } \\
\text { dengan } \\
\text { mesin }\end{array}$ & $\begin{array}{l}\text { memberikan } \\
\text { pelatihan } \\
\text { terkait pada } \\
\text { proses edging } \\
\text { pada setiap } \\
\text { operator }\end{array}$ & HRD \\
\hline & & & & $\begin{array}{l}\text { salah set } \\
\text { up mesin }\end{array}$ & $\begin{array}{c}\text { memberikan } \\
\text { pemahaman } \\
\text { terhadap cara } \\
\text { pengaturan } \\
\text { mesin }\end{array}$ & $\begin{array}{l}\text { kabag. } \\
\text { Produksi } \\
\text { dan } \\
\text { Supervisor } \\
\text { produksi }\end{array}$ \\
\hline & & & metode & $\begin{array}{c}\text { proses } \\
\text { kerja } \\
\text { tidak } \\
\text { sesuai } \\
\text { karena } \\
\text { tidak ada } \\
\text { SOP yang } \\
\text { jelas }\end{array}$ & $\begin{array}{c}\text { pembuatan } \\
\text { SOP tertulis } \\
\text { terkait } \\
\text { denganmetode } \\
\text { pengerjaan } \\
\text { dan set up } \\
\text { mesin }\end{array}$ & QC \\
\hline & & & mesin & $\begin{array}{c}\text { material } \\
\text { terhambat } \\
\text { masuk }\end{array}$ & $\begin{array}{l}\text { penambahan } \\
\text { selang } \\
\text { penghisap } \\
\text { kotoran pada } \\
\text { bagian roller } \\
\text { mesin }\end{array}$ & $\begin{array}{l}\text { kabag. } \\
\text { Produksi }\end{array}$ \\
\hline & & & & $\begin{array}{l}\text { tekanan } \\
\text { angin } \\
\text { terlambat }\end{array}$ & $\begin{array}{l}\text { penambahan } \\
\text { kompresor } \\
\text { agar tekanan } \\
\text { angin tidak } \\
\text { terlambat saat } \\
\text { proses edging } \\
\text { dilakukan }\end{array}$ & $\begin{array}{l}\text { kabag. } \\
\text { Produksi }\end{array}$ \\
\hline & & & & $\begin{array}{l}\text { performa } \\
\text { mesin } \\
\text { tidak } \\
\text { stabil }\end{array}$ & $\begin{array}{c}\text { membuat } \\
\text { jadwal } \\
\text { maintenance } \\
\text { mesin secara } \\
\text { berkala }\end{array}$ & $\begin{array}{l}\text { kabag. } \\
\text { Produksi }\end{array}$ \\
\hline
\end{tabular}




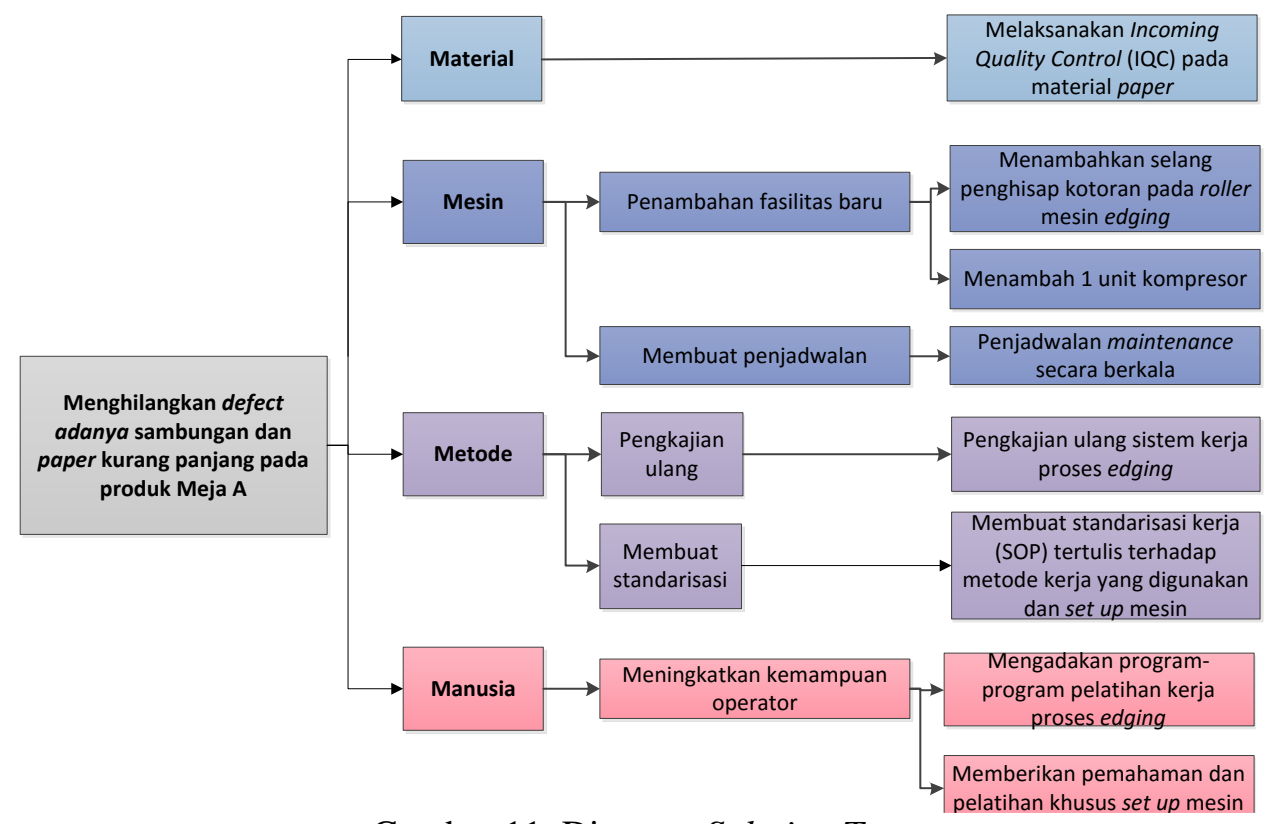

Gambar 11. Diagram Solution Tree

\section{Tahap Control}

Dalam penelitian ini penulis tidak mendapatkan kesempatan untuk mengimplementasikan usulan-usulan perbaikan tersebut sehingga pada tahap control ini akan dijelaskan dalam bentuk masukan untuk perusahaannya dalam hal yang diharapkan akan dapat membantu perusahaan dalam melakukan pengendalian kualitas.

Setelah dilakukan perbaikan dan peningkatan proses pada tahap sebelumnya, perlu dilakukan pengendalian kualitas secara terus menerus agar dapat tercipta suatu kondisi ideal bagi perusahaan. Proses pengendalian kualitas dapat dibantu dengan alat bantu statistik seperti:
a. Check sheet
b. Peta kendali (control chart), khususnya peta kendali $p$
c. Penentuan tingkat sigma
d. Diagram sebab akibat (fishbone diagram)
e. Pendokumentasian

\section{KESIMPULAN}

Berdasarkan hasil pembahasan-pembahasan yang telah dilakukan dapat disimpulkan bahwa:

a. Jenis defect pada komponen produk Meja A pada proses edging adalah adanya edging sambungan, edging paper kurang panjang, dan mentok maal edging-an.

b. Berdasarkan diagram pareto cacat-cacat dominan terjadi pada adanya edging sambungan sebesar $45,2 \%$, edging paper kurang panjang sebesar $41,1 \%$, dan mentok maal edging-an sebesar $13,7 \%$.

\section{JIEMS}

Journal of Industrial Engineering \& Management Systems Vol. 9, No 2, August 2016 c. Faktor-faktor penyebab timbulnya defect pada produk Meja A adalah metode, manusia, mesin, dan material. 
Analisis Pengendalian Kualitas dan Usulan Perbaikan Pada........

JIEMS

Journal of Industrial Engineering \& Management Systems Vol. 9, No 2, August 2016 d. Berdasarkan perhitungan DPMO dan tingkat sigma didapatkan bahwa tingkat sigma dicapai produk Meja A adalah sebesar 4,22 dengan jumlah defect mencapai 73 unit dari 3 jenis CTQ yang ada.

e. Berdasarkan diagram Sebab-Akibat, usulan perbaikan berdasarkan prinsip $5 \mathrm{~W} 1 \mathrm{H}$, dan diagram Solution Tree, disimpulkan bahwa sebagian besar defect disebabkan oleh faktor metode, mesin, manusia, dan material sehingga usulan perbaikan yang dapat diterapkan meliputi:

1. Pengkajian ulang terhadap sistem kerja pada proses edging.

2. Pembuatan standar prosedur dan instruksi kerja (SOP) pada proses edging maupun proses kerja lainya.

3. Menambah fasilitas pada lantai produksi yaitu 1 unit kompresor dan selang penghisap kotoran pada roller mesin edging.

4. Pembuatan standar pengaturan dan penggunaan mesin.

5. Pembuatan jadwal maintenance dan kalibrasi mesin secara berkala.

6. Peningkatan kemampuan operator dengan memberikan pelatihan.

7. Mengadakan IQC (incoming quality control) pada material terutama material paper edging.

\section{DAFTAR PUSTAKA}

Anjayani, Indah, D., 2011. Analisis Pengendalian Kualitas Produk dengan Metode Six Sigma pada CV. Duta Jaya Tea Industri Adiwerna-Tegal [Skripsi].Universitas Negri Semarang, Semarang.

Besterfield, Dale, H., 2009. Quality Control Eight Edition. Pearson Education International, USA.

Chakrabortty, Ripon, K., Biswas, Tarun, K., Ahmed, Iraj. 2013. Reducing Process Variability by Using Dmaic Model: A Case Study In Bangladesh. International Journal for Quality Research, Vol. 7 Iss 1 pp.127-140.

Chandra, C. 2014. Analisis Pengendalian Kualitas dan Usulan Perbaikan di PT Subur Semesta dengan Metode Six Sigma [Skripsi]. Universitas Bunda Mulia Jakarta.

Charde, M. S., Bande, R. T., Walenkiwar, A. S., Kumar, J., Chakole, R. D. 2013. Six Sigma: A Novel Approach to Pharmaceutical Industry. International Journal of Advances in Pharmaceutics, Vol. 2 Iss 6.

Dewi, Shanty, K. 2012. Minimasi Defect Produk Dengan Konsep Six Sigma. Jurnal Teknik Industri, Vol. 13 No.1 Hal. 43-50.

Evans, James, R. dan Lindsay, William, M. 2007. An Introduction to Six Sigma \& Process Improvement. South-Western, Singapore.

Ganguly, K. 2012. Improvement Process for Rolling Mill Through The DMAIC Six Sigma Aproach. Internatiomal Journal for Quality Research. Vol.6 Iss 3 pp. 221-231.

Ghiffari, I., Harsono, A., Bakar, A. 2013. Analisis Six Sigma untuk Mengurangi Cacat Kerja Stasiun Sablon (Studi Kasus: CV. Miracle). Jurnal Online Institut Teknologi Nasional, Vol. 1 No. 1 Hal. 156-165.

Heizer, J. dan Render, B. 2009. Operation Management Flexible Edition. Pearson Education, New Jersey.

Latief, Y. dan Utami, R. P. 2009. Penerapan Pendekatan Metode Six Sigma dalam Penjagaan Kualitas pada Proyek Konstruksi. Makara, Teknologi, Vol. 3 No. 2 Hal. 67-72.

Montgomery, Douglas, C. 2013. Statistical Quality Control Seventh Edition. John Wiley \& Sons, Singapore. 
Analisis Pengendalian Kualitas dan Usulan Perbaikan Pada........
Muttaqien, Achmad, F. 2014. Analisis Pengukuran Kualitas Produk Cacat Pada Mesin Decorative Tiles dengan Metode Six Sigma [Skripsi].Universitas Diponegoro, Semarang.

Riyan. 2013. Usulan Perbaikan Kualitas Proses Produksi Wafer Abon dengan Metode Six Sigma di PT Indosari Mandiri [Skripsi]. Universitas Bunda Mulia Jakarta.

Roesekar, Ravi, S. dan Pohekar, Sanjay, D., 2016. Six Sigma Methodology: A Structured Review. International Journal of Lean Six Sigma, Vol. 5 Iss 4 pp. 392 - 422.
JIEMS

Journal of Industrial Engineering \& Management Systems Vol. 9, No 2, August 2016 